https://doi.org/10.3727/152599519X15506259856381

MS 17020 accepted for publication in Event Management

\title{
LIMINALITY CREATION STRATEGIES AT SUPPLEMENTAL EVENTS
}

Scott Bingley, $\mathrm{PhD}$, Senior Lecturer

Victoria School of Business, Victoria University, PO Box 14428, Melbourne, Victoria, Australia, 8001; Email: Scott.Bingley@vu.edu.au

Corresponding Author: Stephen Burgess, PhD, Honørary Professor

Institute for Sustainable Industries and Liveable Cities, Victoria University, PO Box 14428, Melbourne, Victoria, Australia, 8001; Email:Stephen.Burgess@vu.edu.au

Leonie Lockstone-Binney, PhD, Associate Professor

Department of Tourism, Sport and Hotel Management, Griffith University, Gold Coast, Queensland, Australia, 4222

Email: 1,lockstone-binney@griffith.edu.au

Gerry Urwin, PhD, Associate Professor

Faculty of Business and Law, Coventry University, Priory St, Coventry, UK, CV1 5FB

Email: G.Urwin@coventry.ac.uk 


\begin{abstract}
The celebratory nature that some events generate creates a liminoid space through which participants can obtain social benefits. This paper examines Chalip's five liminality strategies in the context of supplemental events, which are events run in conjunction with major sporting events. The discussion is framed within the context of two supplemental events aligned to the 2015 ICC Cricket World Cup, the Fan Zone and the Trophy Tour. Using 152 short interviews with attendees, the study found some evidence of the presence of Chalip's strategies at these events and that these lead to social benefits. However, the level of liminality and communitas created was minimal, due to the open access nature of the event spaces and also because 'live' World Cup matches were not broadcasted akin to typical 'live sites'. The study contributes to understanding in relation to liminality strategies in the context of supplemental events.
\end{abstract}

Key words: Supplemental events; Case study; Liminality, Fan zone; Trophy tour 


\section{LIMINALITY CREATION STRATEGIES AT SUPPLEMENTAL EVENTS INTRODUCTION}

Major sporting events have been increasingly been employed at a tactical level to engender a range of benefits for host destinations. Chalip (2004, 2006; O’Brien \& Chalip, 2007) has been at the forefront of arguing that the benefits of sporting events can be 'leveraged' in their aftermath to ensure that the considerable investments made in them are optimised. At the heart of the leveraging approach for social benefits is the creation of liminality and communitas. Chalip (2006) described liminality as a sense of something important, perhaps sacred, a feeling or energy that emerges from a community gathering at a major sporting event. This celebratory energy sometimes creates a liminoid (secular) space through which participants can challenge the social boundaries of their everyday lives. The shared sense of community is the resulting communitas. Both liminality and communitas are necessary precursors to leveraging the social benefits of sporting events. Chalip (2006) proposed that a sense of celebration and camaraderie are the two elements underpinning the creation of liminality. He goes onto introduce five strategies for cultivating these elements. There has been limited study of these strategies in the event or sports literature. Chalip provided examples of each strategy but noted "the examples are intended merely as illustrations. There is still a great deal to be learned" (2006, p. 113).

This article examines these strategies in the context of 'supplemental' events (run alongside major sporting events). We examine two events held as part of the 2015 International Cricket Council Cricket World Cup (CWC2015), the Fan Zone and Trophy Tour. The article is structured as follows: the relevant literature is examined, the case study methodology is introduced, and findings and their implications are presented and considered. 


\section{LITERATURE REVIEW}

\section{Sport Event Liminality and Leveraging Strategies}

Over a relatively short period of time, the conceptualisation of sport event leverage has transitioned from a focus on event visitation, trade and media impacts (Chalip, 2004), to a broader model encompassing social benefits (O’Brien \& Chalip, 2007). The social leverage model and its antecedents (liminality and communitas) have been explored in sports event settings. The majority of these studies are quite recent, suggesting that leverage as a research topic is attracting increasing attention (for example, Derom \& VanWynsberghe, 2015; Peachey, Borland, Lobpries, \& Cohen, 2015; Smith, 2010; Sterchele \& Saint-Blancat, 2015).

Chalip (2006) described how events can generate the necessary liminality and communitas in order to create the preconditions for social leverage. Focusing on liminality, Chalip (2006) discussed five strategies by which sporting events could be used to foster social interaction and/or a celebratory space. Briefly, these are:

- Enabling sociability: spaces in, around and/or beyond the event venue for people to gather and socialise - perhaps sharing food, drink and other activities.

- Event related social events: social events or activities specifically created in conjunction with major sporting events, e.g., opportunities for athletes and spectators to interact.

- Informal social opportunities: includes the creation of spaces away from the sporting venue where people can gather; say at 'Live Sites', to watch matches being broadcast.

- Ancillary events: events run in parallel with the sporting event, such as art or cultural festivals, that have specific themes related to the major sporting event. 
- Theme widely: where the "use of event symbols, colours, and decorations provides a visual statement that something special is happening" (Chalip, 2006, p. 117).

Studies support the generation of liminality and communitas at sporting events. Sterchele and Saint-Blancat (2015) in a longitudinal ethnographic study of the annual Anti-Racist World Cup in Italy found that reducing the emphasis placed on the actual sporting contest contributed to creating a liminal space at the event. The conduct of ancillary events ("debates, workshops, exhibitions, cinemas", p. 187) and the enabling of sociability (such as DJs playing music) contributed to the creation of the liminal space. Smith (2010) studied a number of initiatives that a town in South East London had planned to coincide with the UK hosted Stage 1 of the 2007 Tour de France. These included informal social opportunities)(watching the event on giant screens) and ancillary events (such as a fashion show, business events and so forth). Smith found that areas peripheral to the hosting of major events could benefit from leveraging efforts, providing scope for initiatives beyond the immediate bounds of the venue and the host city.

\section{Supplemental Events}

This section examines two supplemental events associated with CWC2015; the Fan Zone and Trophy Tour. McGilliyray and Frew (2015) noted that it has been increasing practice over the last 15 years for special zones (designated for fans to group - 'Fan Zone' in this article) operated as an extension of major sporting events. Fan Zones are temporary structures, usually located in an open area in the host city, either near match venues or in prominent spaces, where matches are typically broadcast on giant screens and different forms of entertainment and activities are provided. Lauss and Szigetvari (2010) suggest that 'fun' is used in Fan Zones "not just as a congregational element, but also a specific organizing principle by which order is maintained" (p. 737). Often these areas have secure access and attendees without matchday 
tickets enter to gain access to the many entertainment options offered and the opportunity to be involved in the 'community' celebrations associated with broadcasts of live sport. McGillivray and Frew (2015, p. 2652) note that Fan Zones extend "beyond mere ancillary events" in reference to Chalip's (2006) terminology “to become carefully planned, orchestrated and mediated events, designed to produce very specific outcomes for host cities and event sanctioning bodies, alike".

Turning to examine Trophy Tours, the most closely recognised tradition related to the modern Trophy Tour is the Olympic torch relay. Sporting Trophy Tours are a relatively recent phenomenon and differ from the Olympic relay in that the actual trophy that is being contested is the focus of the tour. Trophy Tours can occur before or after àn event. After winning the Baseball World Series in the US in 2004, the Boston Red Sox commenced a Trophy Tour that included every city in the state of Massachusetts. The tour had the effect of "creating good will whilst simultaneously helping to attract new fans" (Mnookin, 2007, p. 8). After England won the 2003 Rugby World Cup, the trophy (the Webb Ellis Cup) went on a year long tour across the country to assist efforts to provide a lasting legacy of participation in the game as well as presenting the history of the game's development to the general public. Over one million people viewed the trophy during the tour (Smith, 2012).

These two supplemental events, both held at CWC2015, are now examined for their influence on attendees. The next section outlines the methodology employed in the study.

\section{METHODOLOGY}

The supplemental events examined were the 2015 ICC Cricket World Cup Trophy Tour, held at various locations before CWC2015 commenced (referred to as Trophy Tour hereafter), and the Melbourne Cricket Ground (MCG) Fan Zone, held on days that CWC2015 matches were 
played (referred to as the Fan Zone hereafter). The study involved 152 short interviews (Trophy Tour 100; Fan Zone 52) with visitors to these supplemental events. Full details of the study can be found in Burgess, Bingley \& Urwin (2019). The interviews examined attendees' thoughts and observations about the supplemental events and were conducted from late December 2014 until the end of CWC2015 in March 2015.

\section{FINDINGS}

The Trophy Tour had an international component and 'domestic' legs (various locations in Australia and New Zealand). Five of these locations in the State of Victoria were selected for data collection. Although the activities offered at each site varied, each provided the chance to view and have a picture taken with the trophy, participate in cricket-based activities and watch international cricket on a giant screen (attached to a 'double decker' bus that accompanied the Trophy Tour). The two major reasons visitors attended the Trophy Tour were to view the trophy (and/or get a photograph with it) and to entertain their children. Many of those who attended for the latter reason did so because they described their children as "cricket mad" or they saw an opportunity to keep them occupied during school holidays.

It is important to place the Trophy Tour in the context of liminoid spaces that have been previously studied. It was conducted before CWC2015 commenced, so it would certainly not be considered to be a 'Live Site'. The giant screen showed live international cricket, but not World Cup matches as they were yet to be played. Additionally, there were no restrictions on entry to the Trophy Tour area and there was no security in place (other than near the World Cup trophy). For these reasons, the level of liminality generation associated with the Trophy Tour was unlikely to match the levels that could be achieved in a secured, live site where, say, a key match involving a home country was being broadcast. 
However, it is possible to identify a number of themes that emerged from the Trophy Tour attendees that could be considered to have created other social benefits, even without the existence of liminality or communitas. For instance, many local attendees commented that having the trophy visit their local area was good for the region. Additionally, many commented about seeing people getting together and having fun, specifically with regards to the diversity of attendees and the mixing of different cultures. There was a general recognition that it is good for people of different backgounds to get together, mix and enjoy themselves. There was a general feeling of community spirit, if not quite communitas.

It could be argued that the event organisers were interested in enabling sociability as the intention of the Trophy Tour was to have areas where people could gather and socialise. There was also an intention to create event related social events before CWC2015 matches commenced. Chalip's (2006) theme widely strategy was also adopted, with the CWC2015 branding occurring through the presence of the tour bus and other highly visible signage. This supports the notion that more than one of Chalip's (2006) strategies can apply at the one event, as suggested by Peachey et al.(2015).

Turning to Fan Zones, these were associated with a number of CWC2015 venues. In Melbourne, the official Fan Zone was located in a new area of parkland located between the central business district and the MCG. Data was collected for the study across four of the five Melbourne matches, including the final of the ICC Cricket World Cup.

One of the differences between the Melbourne Fan Zone and others discussed in the literature is that many people were able to get access to tickets for the matches (the MCG having a capacity of around 100,000 spectators) and the match was broadcast on free-to-air television. As such, most of the activity in the Fan Zone occurred before the matches and mainly involved 
people on their way into the stadium. The area became quieter when matches commenced. The other major difference was that there was no fence around the Fan Zone (although the ICC did have a separate area that was fenced off where alcohol was being sold).

Attendees at the Fan Zone were split between those who had planned to attend and casual attendees, mostly passing by on their way to matches. Activities included a giant screen, cricketbased activities and face and nail painting. Most attendees who had planned to visit the Fan Zone had no specific activity in mind. As with the Trophy Tour, seeing people having fun and being active were highlights for attendees, who often referred to the atmosphere of the area as being one of the best aspects of the event. Again, the level of liminality and communitas generated by the Fan Zone did not match the levels of secured, live sites described in the literature. This was likely due to the nature of the space created and the fact that most attendees were also going to the match - the Fan Zone was not 'live'.

The Fan Zone allowed for enabling sociability, providing areas where people could gather and socialise. Similarly, the theme widely strategy was adopted, with CWC2015 branding occurring through recognisable signage. The Fan Zone also provided informal social opportunities (Chalip, 2006), a space where people could gather.

\section{DISCUSSION AND CONCLUSION}

This article explores Chalip's (2006) strategies for generating event liminality and communitas in respect of two different supplemental events. Thus, the study provides insight as to the activities and examples that underpin Chalip's (2006) event liminality strategies in respect of event engagement models not previously examined.

In examining the two supplemental events, we found evidence of some liminality strategies, but little evidence of liminality and perhaps what could be described as 'mild' 
instances of communitas. However, some social benefits were identified, such as benefits of the Trophy Tour for the local region, the enjoyment of people gathering and having a shared, fun experience and the mixing of cultures. Several of Chalip's liminality strategies were at play in respect of the supplemental events: enabling sociability and theme widely at both events and informal social opportunities at the Fan Zone. The results suggest that broader recognition is needed, akin to Peachey et al.'s (2015) findings, that more than one of Chalip's (2006) strategies can apply at the same event. As such, Chalip's strategies can be viewed as a flexible categorisation allowing for multiple liminality creation strategies to be adopted at any one major event or associated supplemental events. Interestingly, the extent of liminality generation and communitas associated with these supplemental events did not appear to be as great, say, compared to previous event leveraging studies and the potential of what could be achieved in a secured, branded Fan Zone. This was likely due to the nature of the spaces created for these supplemental events and the fact that the Trophy Tour and Fan Zones were not actually 'live' sites. People who wanted to see the match live were able to either get tickets to the actual event or watch the match on free-to-air television. However, this did not curb attendees perceiving some social benefits as indicated in the findings.

This study was restricted to supplemental events of CWC2015 in a single State of Australia, although CWC2015 was held across Australia and New Zealand. Whilst this is a limitation, the results suggest that the social benefits of supplemental events are worthy of further examination and that Chalip's strategies remain a useful lens to apply to do this. 


\section{REFERENCES}

Burgess, S., Bingley, S., \& Urwin, G. (2019). Examining the grassroots participant legacy of major sporting 'supplemental' events. Event Management, 23(3).

Chalip, L. (2006). Towards social leverage of sport events. Journal of Sport \& Tourism, 11(2), 109-127.

Chalip, L. (2004). Beyond impact: A general model for sport event leverage. In B. W. Ritchie \& D. Adair (Eds.), Sport tourism: Interrelationships, impacts and issues (pp. 226252). Clevedon, UK: Channel View Publications.

Derom, D., \& VanWynsberghe, R. (2015). Extending the benefits of leveraging cycling events: Evidence from the tour of Flanders. European Sport Management Quarterly, 15(1), 111-131 .

Lauss, G., \& Szigetvari, A. (2010). Governing by fun: EURO 2008 and the appealing power of fan zones. Soccer \& Society, 11(6), 737-747.

McGillivray, D., \& Frew, M. (2015).From fan parks to live sites: Mega events and the territorialisation of urban space. Urban Studies, 52(14), 2649-2663.

Mnookin, S. (2007). Feeding the monster: How money, smarts, and nerve took a team to the top. New York:Simon and Schuster.

O’Brien, D., \& Chalip, L. (2007). Sport event and strategic leveraging: Pushing towards the triple bottom line. In A. G. Woodside \& D. Martin (Eds.), Tourism management: Analysis, behaviour and strategy (pp. 318-338). Oxfordshire: CABI.

Peachey, J. W., Borland, J., Lobpries, J., \& Cohen, A. (2015). Managing impact: Leveraging sacred spaces and community celebration to maximize social capital at a sport-fordevelopment event. Sport Management Review, 18(1), 86-98. 
Smith, A. (2010). Leveraging benefits from major events: Maximising opportunities for peripheral urban areas. Managing Leisure, 15, 161-180.

Smith, J. (2012). Discredited class-war fable or priceless promotion asset: The duality of rugby union's William Webb Ellis foundation myth. In J. Hill, K. Moore, \& J. Wood (Eds.), Sport, history, and heritage: Studies in public representation (pp. 19-32). Croydon, UK: Boydell Press.

Sterchele, D., \& Saint-Blancat, C. (2015). Keeping it liminal. The Mondiali Antirazzati (Antiracist World Cup) as a multifocal interaction ritual. Leisure Studies, 34(2), 182-196. 